\title{
Cross sectional survey of perpetrators, victims, and witnesses of violence in Bogotá, Colombia
}

\author{
L F Duque, J Klevens, C Ramirez
}

J Epidemiol Community Health 2003;57:355-360

See end of article for authors' affiliations

.....................

Correspondence to: Dr L F Duque, Diagonal 29D no 9Sur-90, Apt 1007, Medellín,

Colombia;

Ifduque@epm.net.co

Accepted for publication 22 July 2002

\begin{abstract}
Objectives: To establish the prevalence and distribution of witnesses, victims, and perpetrators of different types of violence in the general population and the proportion of victims consulting health services or reporting the incident to authorities.

Methods: Cross sectional survey of a random sample of 3007 inhabitants between the ages of 15 and 60 in the city of Bogotá, Colombia, in 1997, based on a face to face interview.

Results: Age adjusted past year prevalence of witnesses, victims, and perpetrators of physical aggression was $61 \%, 27 \%$, and $27 \%$, respectively, while lifetime prevalence of witnesses, victims, and perpetrators of assault with a weapon in this population reached $70 \%, 55 \%$, and $5.8 \%$. Between $11 \%$ and $67 \%$ of the victims consulted a health service and less than $32 \%$ reported the incident to an authority. Those involved in most types of physical violence tended to be young, male, from lower middle social classes, with some degree of secondary education, and single or divorced.

Conclusions: Prevalence of witnesses and victims of violence in this sample appears to be high, while perpetrators constitute a small proportion. Violence is not equally distributed throughout the population suggesting the possibility of identifying a population at higher risk for the development of intervention programmes.
\end{abstract}

p ntentional injuries cause $2.7 \%$ of the number of years from premature death and disability in the world. ${ }^{1}$ This burden is even greater among the poorer nations and is projected to increase. The increasing importance of violence as a cause of morbidity and mortality along with its great social and economic costs has lead the World Health Assembly to adopt a resolution declaring it a worldwide public health problem. ${ }^{2}$ To approach violence from a public health perspective, relevant epidemiological information must be collected as a basis for developing programmes for its prevention and control.

Colombia ranks as one of the most violent countries in the world with a rate of 96 homicides per $100000 .^{3}$ In Colombia, violence is the leading cause of death and contributes to $25 \%$ of the burden of disease. ${ }^{4}$ However, data on the magnitude and distribution of violence in Colombia are limited and based on mortality statistics, injuries treated by the health services, or police crime reports. These sources probably underestimate the real magnitude of the problem because of unreported events. In addition, because there are no standardised definitions and records, they might be subject to errors in recording, classification, and interpretation.

The purpose of this study was to establish the prevalence and distribution of witnesses, victims and perpetrators of different types of violence in the general population with standardised measurement techniques. The proportion of victims with injuries who utilised health services or reported the incident to authorities was also assessed to estimate the dimension of unreported incidents of violence and the characteristics of these events.

The study was carried out in Bogotá, the capital of Colombia. Although Bogotá with about six million inhabitants is not the most violent city in the country (it occupies the 15th place among Colombia's capital cities), its homicide rate (44 per 100000 in 1998$)^{5}$ is still disturbingly high compared with international standards.

\section{METHODS}

This cross sectional survey was carried out among a random sample of people between 15 and 60 years of age from the non-institutionalised population in Bogotá. Based on the lowest expected prevalence rate (we expected this to be perpetration of serious violence estimated at 5\%), we wanted at least 30 cases in the strata used for analyses (five strata in the case of age) to provide variation. This resulted in a total sample size of 3000 . This sample size provides estimates with a $99 \%$ confidence intervals and an error of 0.01 .

The sample selection was done in four stages: (1) Bogotá was divided into six geographical regions and a random sample of 200 census tracts was selected, with proportional allocation by population size in each of the six regions; (2) streets were selected randomly from within those tracts; (3) dwellings were listed and then selected randomly on each street; (4) once a person in the household was contacted in the dwelling selected, the interviewer asked for the number of male and female members in the household between the ages of 15 and 60 years and then selected one person with a previously specified random procedure. Because studies have shown that young men have higher rates of violence, we oversampled men between the ages of 15 and 34 to improve the precision of the estimates and conducted the analyses with weights. If the person selected was not at home at that time, the interviewer asked the family member contacted for a convenient day and hour to call or visit the selected person. The interviewer called as many times as necessary to reach the selected person and set an hour and day for the interview. He or she then visited the person's home at that time and up to two times after that if the person was not previously available. Eighty six per cent of those approached $(n=3500)$ agreed to participate in the study for a sample size of 3007. However, participation rates were only $50 \%$ among the upper social class. The main reason for no participation was unavailability of the respondent when the interviewer arrived.

An inventory of different types of violence was developed based on existing measures. ${ }^{6-8}$ Items exploring verbal or psychological violence were: making fun of; tricking, cheating or taking advantage of someone; insulting or humiliating; forcing someone to change residence or pay money; and threats of physical violence. Items for physical violence 
Table 1 Demographic characteristics of the sample compared with 1993 census for Bogotá

\begin{tabular}{lll}
\hline & Sample & Census \\
\hline Age & & \\
$15-19$ & 16.1 & 14.5 \\
$20-24$ & 14.7 & 16.3 \\
$25-34$ & 35.8 & 31.7 \\
$35-44$ & 16.4 & 21.1 \\
$45-60$ & 16.9 & 16.4 \\
Marital status & & \\
Single & 40.9 & 39.1 \\
Married & 31.4 & 31.9 \\
Common law & 19.5 & 18.4 \\
Separated or divorced & 6.5 & 5.8 \\
Widowed & 1.7 & 3.9 \\
Occupation & & \\
Employed & 51.4 & 51.6 \\
Unemployed & 4.1 & 2.9 \\
Retired & 2.7 & 1.9 \\
Student & 21.0 & 21.2 \\
Housewife & 19.4 & 17.8 \\
Other & & 2.5 \\
No information & 1.4 & 2.1 \\
\hline
\end{tabular}

included throwing objects; hitting or slapping; hitting with a belt, stick or rod; robbery; and assault with a weapon. Questions on sexual aggression were limited to having been forced/or forcing someone to have sexual relations or attempts to do so. For all items, we relied on the respondents' interpretation of whatever they considered included in the act mentioned to them.

The pool of items was revised by four experts for content validity and comprehensiveness. The measure was then pre-tested on a convenience sample and validated by the method of known groups. Only those items showing discriminant validity were included in the final questionnaire.

After informing respondents of the objectives of the study and the confidentiality of the information obtained, previously trained interviewers gathered information with a standardised questionnaire in a face to face interview on age, gender, social class (from one to six according to the category that appeared on their utilities bill), level of education, occupation, and marital status. In addition to demographics, respondents were asked about having witnessed, been a victim or perpetrator of multiple incidents of violence in the past year starting with the mildest forms and ending with the most severe forms. An example of a question is: "During the past year, how many times did you see someone insulting or yelling at someone else?", "And how many times did someone do that to you?", "And how many times did you do that to someone else?". For the most severe forms of violence, lifetime prevalence was explored before establishing past year prevalence. The relationship between the victim and perpetrator was also established for the last event in the most severe types of violence. For victims, the occurrence of an injury as a result of the incident, the use of health services and the proportion reporting the incident to authorities were also explored. The questions on violence appeared towards the end of the questionnaire after more general items exploring family and personal characteristics so that interviewers had established an adequate level of rapport with respondents.

As violence is associated with age and age distributions differ among countries, age standardised rates were calculated using the world standard population truncated for the age group 15 to 60 , to facilitate cross national comparisons. ${ }^{9}$

\section{RESULTS}

Forty six per cent of the sample surveyed was male, $30.8 \%$ were between 15 and 24 years of age, and another $35.8 \%$ were between 25 and 34 years of age. Seventy eight per cent of the sample was classified as social class two or three (on a scale of one to six in which one is the lowest social class); $51 \%$ reported being employed while another $21 \%$ reported being a student. Fifty three per cent reported having less than a high school education. The characteristics of this sample as compared with estimates for the same year based on the most recent census data are shown in table 1 . The sample is not significantly different in its distribution of gender, marital status, and occupation to the general population of Bogotá. Because of sampling procedures, there is a greater proportion of people between the ages of 15 and 24 year. However, rates reported have been age adjusted and the data were weighted to correct for the over sampling of young men in all the subsequent analyses.

In this sample, $96.2 \%, 85.8 \%$, and $68.6 \%$ of the population reported witnessing, being a victim of or perpetrating some

Table 2 Age adjusted prevalence per 100 (and $95 \%$ confidence intervals) of witnesses, victims, and perpetrators of different types of violence in the past year among persons aged 15 to 60 in Bogotá, Colombia, 1997

\begin{tabular}{|c|c|c|c|}
\hline \multirow[b]{2}{*}{ In the past year: } & \multicolumn{3}{|c|}{ Prevalence per $100(95 \% \mathrm{Cl})$} \\
\hline & Witnesses & Victims & Perpetrators \\
\hline Made fun of & 65.2 (63.4 to 66.9) & 42.9 (41.1 to 44.8$)$ & 32.6 (30.8 to 34.3$)$ \\
\hline Taken advantage of or tricked & 40.2 (38.3 to 42.0 ) & $25.6(23.9$ to 27.2$)$ & $6.8(5.8$ to 7.7$)$ \\
\hline Yelled at & 76.9 (75.3 to 78.5$)$ & 50.7 (48.9 to 52.6$)$ & 45.9 (44.1 to 47.7$)$ \\
\hline Insulted or humiliated & 55.7 (53.8 to 57.5$)$ & $31.4(29.7$ to 33.1$)$ & 16.6 (15.2 to 17.9 ) \\
\hline Total verbal aggression & $87.0(85.7$ to 88.3$)$ & $68.4(66.6$ to 70.1$)$ & 56.5 (54.6 to 58.3 ) \\
\hline Threw object at & 40.6 (38.8 to 42.4 ) & 19.6 (18.2 to 21.0$)$ & 14.6 (13.3 to 15.9$)$ \\
\hline Hit or slapped & 45.0 (43.2 to 46.9$)$ & $14.7(13.4$ to 16.0$)$ & 13.5 (12.2 to 14.8$)$ \\
\hline Hit with belt, stick or rod & 35.5 (33.7 to 37.3$)$ & $9.0(8.0$ to 10.1$)$ & 11.1 (9.9 to 12.3 ) \\
\hline Total mild physical aggression & 60.7 (58.8 to 62.5$)$ & $27.2(25.6$ to 28.8$)$ & 26.9 (25.2 to 28.5$)$ \\
\hline Armed robbery & $\ldots$ & $5.1 \quad(4.2$ to 5.9$)$ & $0.1(0$ to 0.1$)$ \\
\hline Injured with knife or broken bottle & $\ldots{ }^{*}$ & $0.9(0.6$ to 1.2$)$ & $0.3(0.1$ to 0.5$)$ \\
\hline Shot & $\ldots{ }^{*}$ & $0.6(0.3$ to 0.8$)$ & $0.1 \quad(0.1$ to 0.2$)$ \\
\hline Killed & $\ldots *$ & NA & 0.0 \\
\hline Total assault with a weapon & $\ldots{ }^{*}$ & $5.9(5.0$ to 6.8$)$ & $0.3(0.1$ to 0.5$)$ \\
\hline Attempted to force to have sex & $\ldots{ }^{*}$ & $0.5(0.2$ to 0.7$)$ & $0.04(0$ to 0.1$)$ \\
\hline Forced to have sex & $\ldots *$ & $0.1 \quad(0$ to 0.2$)$ & 0.0 \\
\hline Total sexual aggression & $\ldots{ }^{*}$ & $0.5(0.3$ to 0.7$)$ & $0.04(0$ to 0.1$)$ \\
\hline
\end{tabular}




\begin{tabular}{|c|c|c|c|}
\hline \multirow[b]{2}{*}{ Has ever: } & \multicolumn{3}{|c|}{ Prevalence per $100(95 \% \mathrm{Cl})$} \\
\hline & Witness & Victim & Perpetrator \\
\hline Threats to hit or hurt & 72.4 (70.7 to 74.0 ) & 49.1 (47.2 to 50.9 ) & 35.7 (33.9 to 37.5$)$ \\
\hline Demands or threats to obtain money & 28.1 (26.4 to 29.8 ) & $16.3(14.9$ to 17.7$)$ & $4.1 \quad(3.4$ to 4.8$)$ \\
\hline Threats to force to change residence & 16.4 (15.1 to 17.8$)$ & $7.8(6.7$ to 8.8$)$ & $2.6(2.0$ to 3.2$)$ \\
\hline Threats to hit with belt, stick, or rod & $59.2(57.4$ to 61.1$)$ & 35.7 (33.9 to 37.5$)$ & 24.0 (22.4 to 25.7$)$ \\
\hline Total verbal threats & 80.2 (78.7 to 81.7 ) & 59.4 (57.5 to 61.2$)$ & 41.0 (39.0 to 42.8$)$ \\
\hline Total stolen something of value & 63.3 (61.5 to 65.2$)$ & $51.0(49.1$ to 52.9$)$ & $6.1 \quad(5.2$ to 6.9$)$ \\
\hline Armed robbery & 40.1 (38.2 to 41.9 ) & 21.7 (20.2 to 23.3$)$ & $0.2(0.1$ to 0.4$)$ \\
\hline Threats with knife, or broken bottle & 45.8 (43.9 to 47.7$)$ & 17.6 (16.2 to 19.0$)$ & 3.3 (2.7 to 4.0$)$ \\
\hline Injured with knife or broken bottle & 36.1 (34.3 to 37.9$)$ & $6.0(5.1$ to 6.9$)$ & $1.3(0.8$ to 1.7$)$ \\
\hline Threats with gun & 26.3 (24.6 to 27.9 ) & $8.2(7.2$ to 9.2$)$ & $2.1(1.5$ to 2.7$)$ \\
\hline Shot & 23.9 (22.3 to 25.6$)$ & $3.3(2.6$ to 3.9$)$ & $1.5(1.0$ to 2.1$)$ \\
\hline Killed & $14.2(12.9$ to 15.5$)$ & * & $0.1(0.0$ to 0.3$)$ \\
\hline Total assault with a weapon & $70.1 \quad(68.3$ to 71.8$)$ & $55.0(53.1$ to 56.9$)$ & $5.8(4.9$ to 6.7$)$ \\
\hline Attempted to force to have sex & $7.6(6.7$ to 8.6$)$ & $4.1 \quad(3.4$ to 4.9$)$ & $0.3(0.1$ to 0.5$)$ \\
\hline Forced to have sex & 3.5 (2.8 to 4.2$)$ & $1.3(0.9$ to 1.7$)$ & $0.1 \quad(0.0$ to 0.3$)$ \\
\hline Total sexual aggression & 8.7 (7.7 to 9.7$)$ & 4.6 (3.9 to 5.4$)$ & $0.3(0.1$ to 0.5$)$ \\
\hline
\end{tabular}

type of violence at some time in their life. Table 2 shows the age adjusted estimates (and 95\% confidence intervals) of the prevalence of witnessing or being a victim or perpetrator of each type of violence explored in the past year. In general, the prevalence of different forms of violence in this population tends to occur as a gradient with the less severe forms being most frequent and the most severe forms being comparatively rare. In addition, witnessing violence is more frequent among this population than being a victim and being a victim more frequent than being a perpetrator. The differences between having been a witness or victim compared with being a perpetrator of violence in the past year are greatest for the most severe forms (robbery, assault with a weapon, and sexual aggression).

Table 3 shows the age adjusted estimate (and 95\% confidence intervals) for the lifetime prevalence of witnessing, or being a victim or perpetrator of different types of violence in this random sample. Again, prevalence is highest for the less

Table 4 Prevalence of witnesses, victims, and perpetrators of different types of violence during the past year and over the lifetime by gender, age, and social class among persons aged 15 to 60 in Bogotá, Colombia, 1997

\begin{tabular}{|c|c|c|c|c|c|c|c|c|c|c|}
\hline & \multicolumn{2}{|l|}{ Gender } & \multicolumn{3}{|l|}{ Age } & \multicolumn{5}{|c|}{ Social class } \\
\hline & $\begin{array}{l}\text { Male } \\
n=1395\end{array}$ & $\begin{array}{l}\text { Female } \\
n=1612\end{array}$ & $\begin{array}{l}<25 \\
n=926\end{array}$ & $\begin{array}{l}25-40 \\
n=1411\end{array}$ & $\begin{array}{l}>40 \\
\mathrm{n}=670\end{array}$ & $1 n=159$ & $2 n=1062$ & $3 n=1293$ & $4 n=403$ & $5-6 n=90$ \\
\hline \multicolumn{11}{|c|}{$\begin{array}{l}\text { Past year prevalence of } \\
\text { Verbal }\end{array}$} \\
\hline Witness & 89.1 & 87.8 & 91.9 & 89.7 & 80.6 & 73.9 & 88.6 & 91.0 & 90.4 & 64.9 \\
\hline Victim & 73.0 & 68.6 & 78.3 & 72.1 & 57.2 & 64.0 & 73.2 & 71.0 & 69.5 & 52.9 \\
\hline Perpetrator & 62.6 & 54.9 & 65.4 & 60.0 & 45.6 & 38.2 & 56.7 & 63.5 & 59.5 & 37.5 \\
\hline \multicolumn{11}{|l|}{ Mild physical } \\
\hline Witness & 66.5 & 58.6 & 73.0 & 60.7 & 50.8 & 39.5 & 66.2 & 66.2 & 56.5 & 25.7 \\
\hline Victim & 33.2 & 25.4 & 38.7 & 28.3 & 17.3 & 25.6 & 31.8 & 29.3 & 27.3 & 6.7 \\
\hline Perpetrator & 28.9 & 26.5 & 32.6 & 26.7 & 22.7 & 24.2 & 30.4 & 27.3 & 26.3 & 11.5 \\
\hline \multicolumn{11}{|l|}{ Assault } \\
\hline Victim & 8.3 & 3.8 & 5.7 & 6.0 & 5.9 & 11.8 & 7.8 & 3.9 & 6.1 & 0.4 \\
\hline Perpetrator & 3.8 & 0.1 & 0.2 & 0.3 & 0.4 & 0.0 & 0.4 & 0.2 & 0.4 & 0.0 \\
\hline \multicolumn{11}{|l|}{ Sexual } \\
\hline Victim & 0.5 & 0.8 & 1.3 & 0.4 & 0.0 & 2.5 & 0.8 & 0.3 & 0.2 & 0.0 \\
\hline Perpetrator & 0.1 & 0.0 & 0.0 & 0.1 & 0.0 & 0.0 & 0.2 & 0.0 & 0.0 & 0.0 \\
\hline \multicolumn{11}{|c|}{ Lifetime prevalence } \\
\hline \multicolumn{11}{|c|}{ Theft } \\
\hline Witness & 66.8 & 61.9 & 68.5 & 64.7 & 57.1 & 40.5 & 61.1 & 67.4 & 71.0 & 65.5 \\
\hline Victim & 51.9 & 49.6 & 49.7 & 50.9 & 51.4 & 31.7 & 47.8 & 52.4 & 58.0 & 60.5 \\
\hline Perpetrator & 8.4 & 4.5 & 8.2 & 5.8 & 4.5 & 0.5 & 7.3 & 6.6 & 5.7 & 3.1 \\
\hline \multicolumn{11}{|l|}{ Assault } \\
\hline Witness & 80.0 & 63.6 & 73.8 & 72.3 & 65.1 & 64.0 & 72.8 & 70.5 & 74.1 & 61.0 \\
\hline Victim & 64.9 & 48.3 & 57.9 & 57.1 & 51.0 & 48.6 & 55.3 & 57.9 & 56.7 & 47.4 \\
\hline Perpetrator & 9.1 & 2.8 & 4.4 & 6.6 & 5.8 & 3.5 & 5.4 & 4.8 & 10.5 & 5.8 \\
\hline \multicolumn{11}{|l|}{ Sexual } \\
\hline Witness & 9.3 & 9.2 & 9.4 & 11.4 & 4.6 & 12.9 & 8.6 & 8.7 & 12.4 & 5.1 \\
\hline Victim & 1.4 & 8.6 & 5.9 & 6.4 & 2.2 & 16.0 & 5.3 & 3.6 & 6.8 & 2.9 \\
\hline Perpetrator & 0.8 & 0.1 & 0.2 & 0.7 & 0.2 & 0.0 & 0.2 & 0.4 & 1.4 & 1.2 \\
\hline
\end{tabular}


Table 5 Prevalence of witnesses, victims, and perpetrators of different types of violence during the past year and over the lifetime by level of education, marital status, and employment among persons aged 15 to 60 in Bogotá, Colombia, 1997

\begin{tabular}{|c|c|c|c|c|c|c|c|c|c|}
\hline & \multicolumn{3}{|c|}{ Years of education } & \multicolumn{3}{|c|}{ Marital status } & \multicolumn{3}{|c|}{ Employment status } \\
\hline & $<6 n=259$ & $\begin{array}{l}6-10 \\
n=1338\end{array}$ & $\begin{array}{l}11 \dagger \\
n=1410\end{array}$ & $\begin{array}{l}\text { Married } \\
n=1531\end{array}$ & $\begin{array}{l}\text { Single* } \\
n=1425\end{array}$ & $\begin{array}{l}\text { Widowed } \\
n=51\end{array}$ & No $n=123$ & $\begin{array}{l}\text { Yest } \\
n=2177\end{array}$ & $\begin{array}{l}\text { Retired } \\
\mathrm{n}=81\end{array}$ \\
\hline \multicolumn{10}{|c|}{ Past year prevalence of } \\
\hline Witness & 77.5 & 91.0 & 91.1 & 85.9 & 91.4 & 79.8 & 85.9 & 88.7 & 75.2 \\
\hline Victim & 59.8 & 74.6 & 72.4 & 65.5 & 76.7 & 56.9 & 77.2 & 70.5 & 60.4 \\
\hline Perpetrator & 45.9 & 60.6 & 62.2 & 53.6 & 64.0 & 47.2 & 59.0 & 58.6 & 44.7 \\
\hline \multicolumn{10}{|l|}{ Mild physical } \\
\hline Witness & 49.3 & 69.7 & 62.4 & 56.2 & 68.5 & 69.9 & 61.7 & 62.5 & 48.1 \\
\hline Victim & 27.2 & 33.9 & 26.4 & 24.3 & 34.0 & 33.1 & 32.6 & 29.1 & 27.8 \\
\hline Perpetrator & 25.3 & 33.7 & 24.3 & 25.9 & 29.3 & 32.5 & 31.2 & 27.7 & 22.7 \\
\hline \multicolumn{10}{|l|}{ Assault } \\
\hline Victim & 5.0 & 6.4 & 5.9 & 5.2 & 6.8 & 2.6 & 4.8 & 6.0 & 2.6 \\
\hline Perpetrator & 0.4 & 0.2 & 0.3 & 0.3 & 0.2 & 1.6 & 0.5 & 0.3 & 0.0 \\
\hline \multicolumn{10}{|l|}{ Sexual } \\
\hline Victim & 0.2 & 1.0 & 0.5 & 0.3 & 1.0 & 0.0 & 3.6 & 0.5 & 0.0 \\
\hline Perpetrator & 0.0 & 0.0 & 0.1 & 0.0 & 0.1 & 0.0 & 0.0 & 0.1 & 0.0 \\
\hline \multicolumn{10}{|c|}{ Lifetime prevalence } \\
\hline \multicolumn{10}{|c|}{ Theft } \\
\hline Witness & 50.8 & 64.2 & 69.8 & 60.1 & 68.7 & 59.5 & 53.4 & 64.6 & 69.4 \\
\hline Victim & 42.0 & 51.3 & 53.9 & 49.0 & 52.4 & 55.3 & 46.2 & 50.8 & 61.4 \\
\hline Perpetrator & 6.2 & 6.9 & 5.9 & 5.7 & 7.1 & 2.5 & 7.2 & 6.0 & 13.7 \\
\hline \multicolumn{10}{|l|}{ Assault } \\
\hline Witness & 59.6 & 74.8 & 73.4 & 69.6 & 73.2 & 59.5 & 81.5 & 70.7 & 73.3 \\
\hline Victim & 49.6 & 57.7 & 57.6 & 52.8 & 59.6 & 51.6 & 53.5 & 56.4 & 51.0 \\
\hline Perpetrator & 5.3 & 4.5 & 6.8 & 6.2 & 5.1 & 8.6 & 5.1 & 5.5 & 14.8 \\
\hline \multicolumn{10}{|l|}{ Sexual } \\
\hline Witness & 7.4 & 9.8 & 9.6 & 9.0 & 9.7 & 4.8 & 8.9 & 9.5 & 4.8 \\
\hline Victim & 4.8 & 6.1 & 4.9 & 4.8 & 5.9 & 3.2 & 7.0 & 5.4 & 0.0 \\
\hline Perpetrator & 0.4 & 0.2 & 0.6 & 0.1 & 0.7 & 0.7 & 0.3 & 0.5 & 0.0 \\
\hline
\end{tabular}

severe forms of violence and lowest for the most severe forms. Similarly, witnessing violence is much more frequent than being a victim and there are far less perpetrators than victims. The differences are greatest for the most severe forms of violence. While there are two perpetrators for every three victims of the milder forms of violence there are 10 victims for each perpetrator for the more severe forms.

Table 4 shows the prevalence rates of witnesses, victims, perpetrators of violence by age, gender, and social class. In general, men reported significantly higher rates of involvement in violence except for witnessing verbal or sexual aggression and perpetrating mild physical aggression while women reported higher victimisation rates for sexual aggression. The highest gender proportional difference is observed in assault with a weapon: 38 times more among men than among women during past year. Younger subjects reported significantly more involvement in all types of violence except for assault with a weapon (as victims and perpetrators) in the past year and lifetime prevalence of being a victim of theft or a perpetrator of assault with a weapon or sexual aggression.
The lowest and highest social classes ( 1 and 5-6 respectively) tended to have the lowest rates of all types of violence with some exceptions. Those in the highest social class reported the highest rates of theft victimisation and witnessing during their lifetime while the lowest social class reported the highest lifetime rates of sexual victimisation as well as assault victimisation with a weapon in the past year.

Violence rates also varied by level of education and marital status ( see table 5). Those with the lowest level of education or married tended to have lower rates of involvement in violence. On the other hand, being unemployed was not consistently associated with higher rates of violence.

Table 6 presents the proportion of victims of the most severe events who sustained injuries, consulted a physician or health service or reported the incident to authorities. Violence producing injury was highest for victims of assault with a knife and lowest for victims of armed robbery. Between 5\% and $31 \%$ of the victims reported the incident to authorities. Of those injured, between $56 \%$ and $79 \%$ consulted a physician or health service for that injury.

Table 6 Proportion of victims injured, utilising health services (in the total population and among those injured) or reporting incident to authorities among persons 15 to 60 in Bogotá, Colombia, 1997

\begin{tabular}{lllll}
\hline Was a victim of & \% injured & $\begin{array}{l}\text { \% of victims who } \\
\text { consulted }\end{array}$ & $\begin{array}{l}\text { \% of injured who } \\
\text { consulted }\end{array}$ & $\begin{array}{l}\text { \% reported to } \\
\text { authorities }\end{array}$ \\
\hline Armed robbery & 18.7 & 11.4 & 61.3 & 4.9 \\
Assault with knife & 90.2 & 67.0 & 74.4 & 28.6 \\
Assault with firearm & 38.9 & 30.3 & 78.9 & 31.5 \\
Attempted rape & 26.0 & 16.7 & 74.2 & 15.8 \\
Rape & 65.7 & 36.6 & 55.6 & 30.8 \\
\hline
\end{tabular}




\section{Key points}

- While witnessing or being a victim of violence is widespread in this Bogota, Colombia, sample, perpetration of violence seems to be limited to a small sector of the population.

- Involvement in violence is not randomly distributed throughout the population suggesting that there are groups at higher risk that could be targeted for intervention.

The relationship between victims and perpetrators was established for the last event. Victims reported that strangers had been the perpetrators for almost all the incidents of theft and around half the incidents of assault with a weapon. Friends or acquaintances were reported to be the perpetrators of $42 \%$ of the assaults with knives and $32 \%$ of the assaults with firearms. They were also reported to be the perpetrators of sexual aggression in $42 \%$ of the cases of attempted rape and $28 \%$ of the cases of rape. On the other hand, family members were reported to be the perpetrators of sexual aggression in about $32 \%$ of the cases. Perpetrators also reported that strangers were the main victims of robbery, assault with a weapon and homicide followed by friends or acquaintances. However, in the case of sexual aggression, they reported that their victims had almost always been their spouse or partner.

\section{DISCUSSION}

The findings from this cross sectional survey of violence among a large random sample of the general population between the ages of 15 and 60 in Bogotá, Colombia show that almost everybody has been a witness of some type of violence while about $86 \%$ have been victims and $68 \%$ have been perpetrators. In general, verbal and mild physical aggression are frequent while theft, assault and sexual aggression are comparatively rare in the general population. Young men from the lower middle social class, with some degree of secondary education, and single or divorced tend to be involved in most types of violence but women reported higher rates of sexual victimisation and similar rates to male rates for involvement in verbal and mild physical violence.

Before discussing the results of this survey in Bogotá and its possible implications, various methodological limitations must be acknowledged. Firstly, the results are based on retrospective self reports obtained in a household interview and thus are subject to problems of recall (especially lifetime prevalence) and social desirability. Moreover, respondents reported on their own experiences as targets before reporting their experiences as aggressors, which may have predisposed them to underestimate their own aggressiveness. Consequently, even though research suggests that self reported victimisation and offending are better estimates of their real magnitude, ${ }^{10}{ }^{11}$ the rates presented here may still be an underestimate, especially for the less severe forms of violence.

The results may also be biased by the possible differences between participants and non-participants. Although the participation rate was acceptable for a survey of this sort (86\%), it was much lower among the higher social classes and we lack other information that could help us establish the possible effects this might have had on the results. In addition, as we excluded the incarcerated and other institutionalised populations as well as those without dwellings, the results may not apply to these special groups. Unfortunately, we lack information on the sizes of these excluded population groups, some with expectedly high rates of violence (for example, prisoners and homeless) and others with very low rates (such as convents) and so cannot provide an estimate of the impact their exclusion could have had on the data.

Despite these and other limitations, the main strengths of this study are that it provides population based estimates of involvement in violence in a non-English speaking less developed country, and that it presents data on perpetrators. To facilitate comparisons across countries, these rates have been adjusted for age and calculated for specific acts of violence.

There are comparatively few prevalence studies of violence based on random samples of the general population in the published literature and most focus on victimisation. In comparing our data to other similar studies, caution must be observed as prevalence rates may vary because of characteristics of the sample, data collection methods, and the type, context and time frame of questions used. With this cautionary note in mind, we will compare our data to similar studies found in the published literature.

One of the few studies to establish the prevalence of witnesses of violence among a large random sample was a study of Canadians 20 years and older in the city of Thunder Bay, Ontario. ${ }^{12}$ In this Canadian sample $34 \%$ had been witnesses of some form of physical aggression in the past year which is about half of what we found in Bogotá, even though the Canadian questionnaire included various forms of aggression such as punching, kicking, grabbing, pushing or shoving which were not explored in our sample. While only $1.1 \%, 3.4 \%$, and $1.4 \%$ of the Canadian sample reported having seen someone throw an object, hit or slap someone, or hit someone with an object, respectively, the Bogotá sample reported 19.6\%, $14.7 \%$, and $9.0 \%$ for these same acts of violence.

There are several population based prevalence studies on victimisation. The United Nations Interregional Crime and Justice Research Institute has conducted a survey of criminal victimisation based on random samples of the populations in major cities in various developing countries, including three countries in Latin America. ${ }^{13}$ They report past year and past five year prevalence of burglary, robbery, personal theft, assault (including threats with and without arms), and sexual incidents. Among these, perhaps the most comparable categories to our data are assault and sexual incidents in the past year. While $1.5 \%$ and $0.3 \%$ of our sample reported having been assaulted with an arm or forced (or tried to force) to have sex respectively, the rates for the 13 cities surveyed in the United Nations study varied between $1.1 \%$ and $10.3 \%$ for assault and 0.6 and 11.8 for sexual incidents. Compared with the United States, being a victim of assault is about 1.4 times more frequent in Bogotá, of theft is eight times more frequent, and sexual assault is three times more frequent than the rates reported in the National Crime Victimization Survey ${ }^{14}$ although this survey is limited to victimisation in the past six months and the questions and categories may not be fully comparable. Our rates for being a victim of armed robbery and injuries with a knife or gun are also within the ranges reported by another study on victimisation, which was carried out by the Pan American Health Organization (the ACTIVA study) in seven cities of Latin America and Madrid. ${ }^{15}$ However, compared with these same cities, being a victim of mild physical aggression is about twice as likely in Bogotá.

According to our findings, between $5 \%$ and $31 \%$ of the victims actually report most incidents to authorities. Although similar rates of underreporting are found in the developing countries surveyed by the United Nations' study $^{13}$ in these countries sexual incidents appear to be the least reported while in Bogotá, being a victim of armed robbery was the least reported. Far more events come to the attention of health care providers, especially when victims have been injured, they range between $55 \%$ for rape and $75 \%$ for assault with a firearm incidents. Further research is needed to identify the factors associated with the differential reporting and use of services to better understand the populations being served and the barriers to these services.

The ACTIVA study carried out by the Pan American Health Organization also explored perpetration of violence towards children, intimate partners and non-family members. ${ }^{16}$ Among the questions in the study, one explored the frequency 
of hitting a partner or a child with an object, a question similar to one in our study. In the ACTIVA study, prevalence rates in the seven cities ranged from $0 \%$ to $7.1 \%$ for hitting a partner with an object in the past year, while hitting a child with an object varied between $0.9 \%$ and $13.3 \%$ among men and $4.4 \%$ to $26.9 \%$ among women. The highest rates in all types of violence in the ACTIVA study were reported in Cali, another Colombian city. In our sample, almost $12 \%$ reported hitting someone (we did not differentiate whom) with an object with no difference between sexes. We suspect that our rate for this question is underestimated as we did not specifically explore this behaviour in the context of domestic violence.

To a similar question posed in the 1990 National Alcohol Survey for a large random sample of persons 18 and over in the continental United States, $10.1 \%$ reported that they had "hit someone with an object, beat someone up or attacked someone" since they were 12 years of age. ${ }^{17}$ This rate is a bit lower than ours even though we only explored this behaviour in the past year and their measure includes other types of violence among an older sample. However, this study also reports a rate of $0.3 \%$ for sexual aggression, which is similar to the rate found in our sample.

Rates for assault with a weapon tend to be lower in the United States compared with our sample. The Epidemiologic Catchment Area Survey reports that $1.1 \%$ of their large random sample from three cities "have ever used a weapon like a stick, knife or gun in a fight since the age of eighteen"18 and the National Household Survey on Drug Abuse, which used a self administered questionnaire, reports that $0.3 \%$ of their large random sample have used a gun in the past year. ${ }^{19}$

In this study, the prevalence of perpetrators was especially small compared with witnesses and victims for the most serious types of violence. This is consistent with the evidence from various longitudinal studies showing that serious offending and aggression are in fact limited to less than $10 \%$ of the population. ${ }^{20}$ The findings also show that violence is not equally distributed throughout the population and instead was significantly associated with place of residence, social class, gender, occupation, level of education, and marital status. In general, those involved in most types of physical violence (witnesses, victims, and perpetrators) tended to be young, male, from lower middle social classes, with some degree of secondary education, single, or divorced. Sexual aggression, on the other hand, did not show many differences in its distribution in the population except for its greater number of female victims from the lowest social classes and the greater number of male perpetrators. Both these findings tend to be consistent with data from other countries.

The descriptive data in this report show that violence is not a random event but instead is concentrated in certain segments of the population. Policy and programme developers to target these high risk groups for their prevention and treatment priorities should use this information. This is especially important in the case of perpetrators of violence. Considering that they seem to be a very small proportion of the total population, the identification of high risk offenders groups is desirable to orient violence control and prevention interventions. Violence prevention and control policies and programmes could be better targeted if developing countries have more data on aggressors. A better understanding of the social, cultural, and familial factors that underlie this differential distribution will help in the design of appropriate preventive programmes.
The information from surveys such as this one may serve as a baseline estimate of violence and facilitate future analyses of time trends or evaluation of interventions.

\section{Authors' affiliations}

L F Duque, School of Public Health, University of Antioquia, Medellin, Bogotá

J Klevens, ASSALUD, Bogotá and Programa de Convivencia

Ciudadana, Medellín, Bogotá

C Ramirez, School of Psychology, Universidad San Buenaventura, Bogotá

Funding: this study was supported by Colciencias and the Asociación Colombiana para la Salud (ASSALUD), Colombia.

Conflicts of interest: none.

\section{REFERENCES}

1 Murray CJ, Lopez AD, eds. The global burden of disease. Cambridge, MA: Harvard University Press, 1996:374.

2 World Health Assembly. Prevention of violence: public health priority. Geneva: WHO, 1996.

3 Pan American Health Organization. Health conditions in the Americas. Washington, DC: PAHO, 1998. (Scientific publication no 569 , vol 1)

4 Ministerio de Salud, Colombia. La carga de la enfermedad en Colombia [The burden of disease in Colombia]. Bogotá: Ministerio de Salud, 1994.

5 Instituto Nacional de Medicina Legal y Ciencias Forenses, Colombia. Forensis, 1999. Panamericana, Bogotá: Instituto Nacional de Medicina Legal y Ciencias Forenses, 2000.

6 Strauss MA. Measuring intrafamily conflict and violence: the Conflict Tactic Scales. In: Strauss MA, Gelles RJ, eds. Physical violence in American families: risk factors and adaptations to violence in 8145 families. New Brunswick, NJ: Transaction Publications, 1990.

7 Buss AH. The psychology of aggression. New York: Wiley, 1961:171-3.

8 Fournier $M$, de los Ríos R, Orpinas $P$, et al. Multicenter study: cultural norms and attitudes toward violence in selected cities of Latin America and Spain (ACTIVA project). Rev Panam Salud Publica 1999;5:222-31.

9 World Health Organization. World Health Statistics Annual. Geneva: WHO, 1996:XXVI.

10 Hilton NZ, Harris GT, Rice ME. On the validity and reliability of self-reported rates of interpersonal violence. Journal of Interpersonal Violence 1998;13:58-72.

11 Huizinga D, Elliot DS. Reassessing the reliability and validity of self-report delinquency measures. Journal of Quantitative Criminology 1986;2:293-327

12 Pernanon, K. Alcohol in human violence. New York: Guilford Press, 1991.

13 Zvekic U, del Fate AA, eds. Criminal victimisation in the developing world. Rome: United Nations Interregional Crime and Justice Research Institute Publication no 55, 1995.

14 Office of Justice Programs. Criminal victimization in the United States. Washington, DC: OJP, 1994.

15 Cruz JM. La victimización por violencia urbana: niveles y factores asociados en ciudades de América Latina y España. [Being a victim of urban violence: its likelihood and its associated variables on cities of Latin America and Spain]. Rev Panam Salud Publica 1999;5:259-67.

16 Orpinas $\mathbf{P}$. Who is violent?: factors associated with aggressive behaviors in Latin America and Spain. Rev Panam Salud Publica 1999;5:232-44.

17 Greenfield TK, Weisner, C. Drinking problems and self-reported criminal behavior, arrests, and convictions: 1990 US alcohol and 1989 County surveys. Addictions 1995:90:361-73.

18 Swanson JW, Holzer CE, Ganju VK, et al. Violence and psychiatric disorder in the community: evidence from the epidemiologic catchmen area surveys. Hospital and Community Psychiatry 1990;7:761-70.

19 Harrison L, Gfroerer J. The intersection of drug use and criminal behavior. Results from the national household survey on drug abuse. Crime and Delinquency 1992;38:422-43.

20 Tolan, PH, Gorman-Smith, D. Development of serious and violent offending careers. In: Loeber R, Farrington DP, eds. Serious and violent juvenile offenders. Risk factors and successful interventions. Thousand Oaks, CA: Sage, 1998:72. 